\section{STARS OF SOUTH AMERICAN SCIENCE}

\section{Growing resources for research and development are creating opportunities across the continent, but many} countries still struggle to build their programmes.

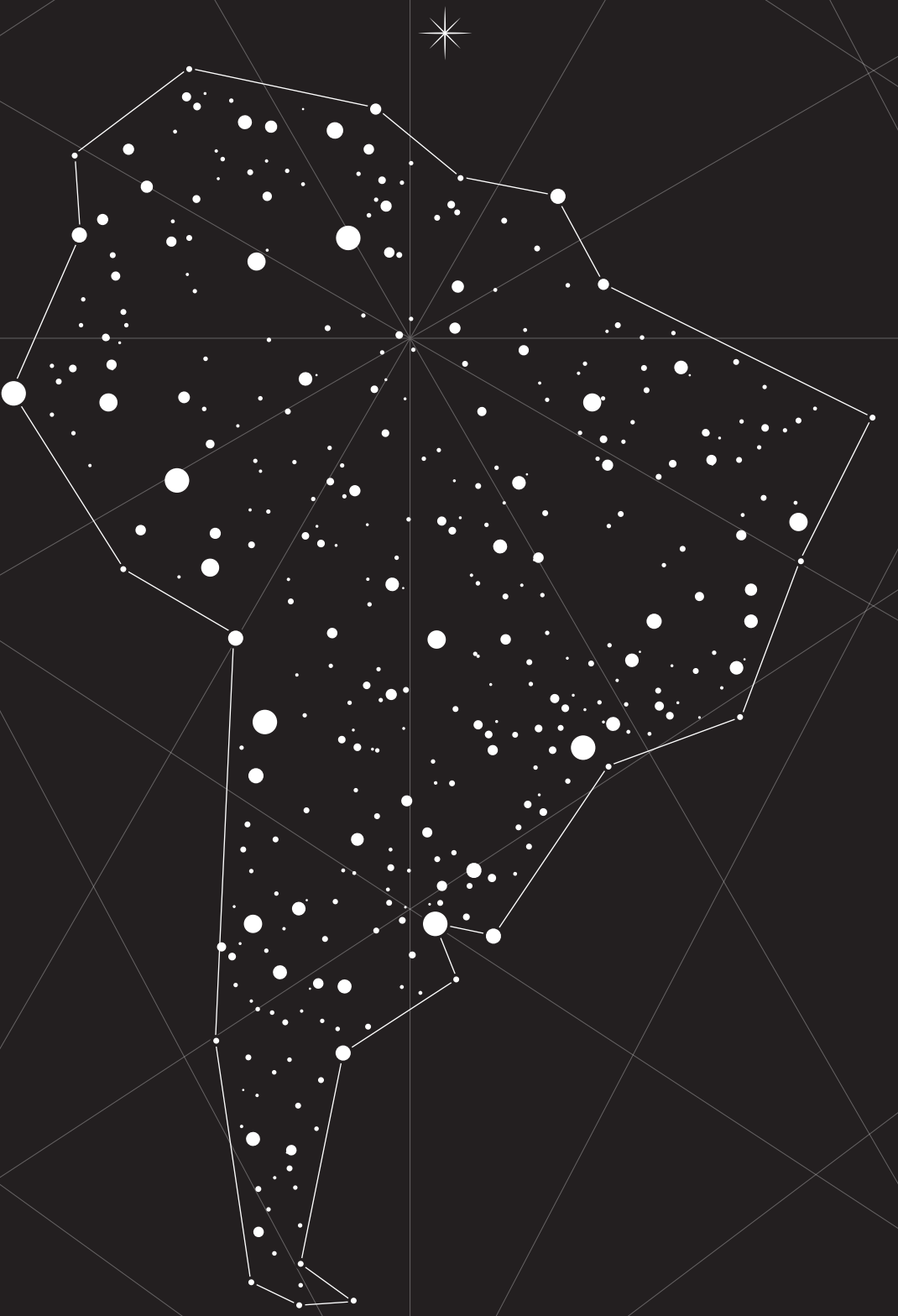

ike the night sky, the overall sweep of science in South America can look pretty dark. Brazil is the only country on the continent that spends more than $1 \%$ of its gross domestic product on research and development, and even that investment sits far below what other countries of similar means are ploughing into science.

But take a closer look at the continent's scientific enterprise, and bright spots emerge. At the start of the FIFA World Cup in Brazil, with billions of people focusing on South America, Nature examines a part of the world that has spent too long on the sidelines of science.

A graphic tour on page 202 details the inputs and products of research and development on the continent. The region faces many challenges in terms of building a strong scientific workforce and boosting resources, but investment and publications are climbing. A News Feature on page 204 profiles several key institutions and research groups - from agricultural specialists in Colombia to RNA experts in Argentina who have gained worldwide recognition.

An Editorial on page 188 calls on international colleagues to help build South American science in ways that do not cause young researchers to leave permanently. On page 213, a Comment describes one such success: the Pew Latin American Fellows Program, which each year sends about ten top graduates to work in North American labs. More than 70\% return to their native countries, bringing with them the expertise they have gained. That initiative is a part of broader efforts, described in a News Feature on page 207 that examines how countries are trying to repatriate scientists who left to train abroad.

As economies on the continent heat up, they are devoting greater resources to research, increasing the need for better infrastructure and policies to support science. In a Comment on page 209, research leaders describe how they hope to navigate this growth, and how science can help to expand their countries' economies sustainably. Ideas range from creating a science ministry to using research to find new commercial uses for the fruits of the Amazon.

Many researchers in South America maintain a cautious outlook - they have lived through periods of intense economic and political strife in the not-too-distant past. But they also harbour the hope that the continent's science is headed for a winning season.

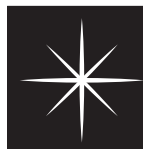

SOUTH MMEPICIN SCIENCE

A Nature special issue nature.com/southamerica 